\title{
Physalin A regulates the Nrf2 pathway through ERK and p38 for induction of detoxifying enzymes
}

\author{
Ji Min Shin ${ }^{1,2}$, Kyung-Mi Lee ${ }^{1}$, Hee Ju Lee ${ }^{3}$, Ji Ho Yun ${ }^{1}$ and Chu Won Nho ${ }^{1,2^{*}}$
}

\begin{abstract}
Background: Physalin A isolated from Physalis alkekengi var. franchetii has been known to have many pharmacological properties. However, its effect through the Nrf2 pathway has not yet been elucidated. In the present study, we determined the effects of physalin A on cancer chemoprevention via the Nrf2 pathway.

Methods: Experiments were performed in Hepa-1c1c7 and HepG2 cells. The quinone reductase (QR) activity assay was used to assess the activity of physalin A and other compounds isolated from P. alkekengi. The antioxidant response element (ARE) reporter assay was used to determine physalin A induced transcription of Nrf2 target genes, whereas the oligonucleotide pull-down assay was used to investigate Nrf2 binding to the AREs post physalin A treatment. Real-time PCR and western blotting were performed to determine the expression of Nrf2 target genes. Immunocytochemistry was used to determine Nrf2 localization after treatment with physalin A. Kinase inhibitors were used to test the involvement of Nrf2-targeting kinases and the role of ERK and p38 phosphorylation was confirmed using western blotting.

Results: Physalin A significantly induced QR activity. As an upstream effector of QR, Nrf2 induced genes containing the ARE, which encode various antioxidants and detoxification enzymes. We observed that physalin A increased the expression of Nrf2 and its target genes in HepG2 cells. Moreover, we observed that physalin A-induced Nrf2 activation was regulated by ERK and p38 kinase in HepG2 cells.
\end{abstract}

Conclusions: Taken together, we showed that physalin A increased detoxifying enzyme expression via activation of Nrf2 and its target genes. These results imply that physalin A could be a potential chemopreventive agent for liver diseases, as well as cancer.

Keywords: Physalin A, Cancer chemoprevention, Quinone reductase, NF-E2-related factor 2, Extracellular signalregulated kinase, p38 mitogen-activated protein kinase

\section{Background}

Liver cancer, the fifth-most common cancer worldwide, is the third-most common cause of mortality due to cancer [1]. Furthermore, liver cancer-associated mortality in both men and women is higher than the diagnostic rates [2]. Thus, prevention of liver cancer is of utmost importance. Synthetic or natural pharmaceutical agents mainly used, especially, traditional medicine is useful to prevent the

\footnotetext{
* Correspondence: cwnho@kist.re.kr

${ }^{1}$ Natural Products Research Center, Korea Institute of Science and

Technology (KIST) Gangneung Institute of Natural Products, Gangneung, Gangwon-do 25451, Republic of Korea

${ }^{2}$ Division of Bio-Medical Science \&Technology, KIST School, Korea University of Science and Technology, Seoul 02792, Republic of Korea

Full list of author information is available at the end of the article
}

development of various diseases, including cancer due to their safety and affordability [3-5].

Phytochemicals, especially plant-derived compounds, are used in clinical trials as cancer chemopreventive agents [6]. For example, sulforaphane is a representative phytochemical obtained by hydrolysis of glucoraphanin, which is abundant in broccoli. Sulforaphane inhibits cancer growth and the overall carcinogenetic process by inducing phase II enzymes, including quinone reductase $(\mathrm{QR}, \mathrm{NAD}(\mathrm{P}) \mathrm{H}$ : quinone oxidoreductase) and glutathione $\mathrm{S}$-transferases (GSTs) [6, 7].

Nuclear factor erythroid 2-related factor 2 (Nrf2), a member of the basic leucine zipper transcription factor family, regulates the expression of genes containing the 
antioxidant response element (ARE) in the promoter region, which are related to antioxidation and detoxification. Under normal conditions, Nrf2 dimerizes with Kelch-like ECH-associated protein 1 (Keap1) [8] (Fig. 1). Nrf2 protects cells from stress inducers such as endogenous reactive molecules, radiation, and environmental toxins [9]. When cells are exposed to stress, Nrf2 separates from Keap1 in the nucleus and activates its target genes [10]. Several kinases such as ERK1/2, PKC, PI3K, and AMPK regulate Nrf2 expression [11-14].

Nrf2 targets such as heme oxygenase-1 (HO-1), $\mathrm{NAD}(\mathrm{P}) \mathrm{H}$ quinone oxidoreductase (NQO-1), and GSTs encode phase II detoxification enzymes [15]. HO-1, a cytoprotective enzyme, regulates antioxidative and inflammatory responses, and NQO-1 is involved in detoxification [8], which may inhibit cancer initiation by detoxifying and eliminating carcinogens [16]. In addition, previous studies have reported an association of the QR-encoding gene with risks of developing various cancers $[17,18]$. Therefore, QR can be targeted for developing potential cancer chemopreventive agents.

Physalis alkekengi var. franchetii (Solanaceae) is found in East Asia and is known to ameliorate otitis media, fever, sore throat and renal diseases [19] [20]. Physalin A, one of the major bioactive compounds isolated from P. alkekengi possesses many pharmacological properties, including antifungal, anti-cough, anti-inflammatory, and analgesic activities in vivo and in vitro [21]. Physalin A induces apoptotic cell death in various cell lines and induces G2/M cell cycle arrest in human lung cancer cells $[22,23]$. However, the chemopreventive effect of physalin A via the Nrf2 pathway has not yet been elucidated.

In this study, we investigated the effect of $P$. alkekengi and physalin A on cancer chemoprevention via the Nrf2 pathway. Physalin A induced Nrf2 and its target genes encoding HO-1 and NQO1 via ERK and p38 kinases in HepG2 cells.

\section{Methods}

\section{Chemicals and reagents}

$P$. alkekengi was purchased from a Kyungdong oriental herbal market, Seoul, Republic of Korea. The voucher specimens (ND4) have been deposited at the Systems Biotechnology Research Center, KIST, Gangneung Institute of Natural Products, Republic of Korea. This plant identified by Dr. Hak Cheol Kwon who responsible for KIST natural products library at KIST Gangneung, institute of natural products. Dried P. alkekengi $(2.5 \mathrm{~kg})$ were extracted using $95 \%$ ethanol for $4 \mathrm{~h}$ by reflux. After filtration, the ethanol were evaporated in a vacuum to obtain the ethanol extract ( $203 \mathrm{~g}$ ), which was suspended in distilled water and partitioned using n-hexane, ethyl acetate, and n-butanol. The ethyl acetate fraction (15 g) was chromatographed on a Sephadex LH-20 column, eluted using methanol to obtain five fractions (fractions 1-5). Physalin A was re-chromatographed from fraction 3 using Sephadex LH-20 (methanol) and RP-18 gel [methanol-water $(40 \rightarrow 70 \%, v / v)]$ column chromatography to obtain white crystals. The chemical structures of compound 1 was determined by ${ }^{1} \mathrm{H}$ and ${ }^{13} \mathrm{C}$ nuclear magnetic resonance and the results were compared with published data [24].

Dulbecco's high glucose modified Eagle medium (DMEM) (Hyclone, Logan, UT, USA), fetal bovine serum (FBS), $100 \mathrm{U} / \mathrm{ml}$ penicillin, and $100 \mu \mathrm{g} / \mathrm{ml}$ streptomycin were obtained from Thermo Scientific (Waltham, MA, USA). 3-(4,5-Dimethyl-2-thiazolyl)2,5-diphenyl-2H-tetrazolium bromide (MTT) and

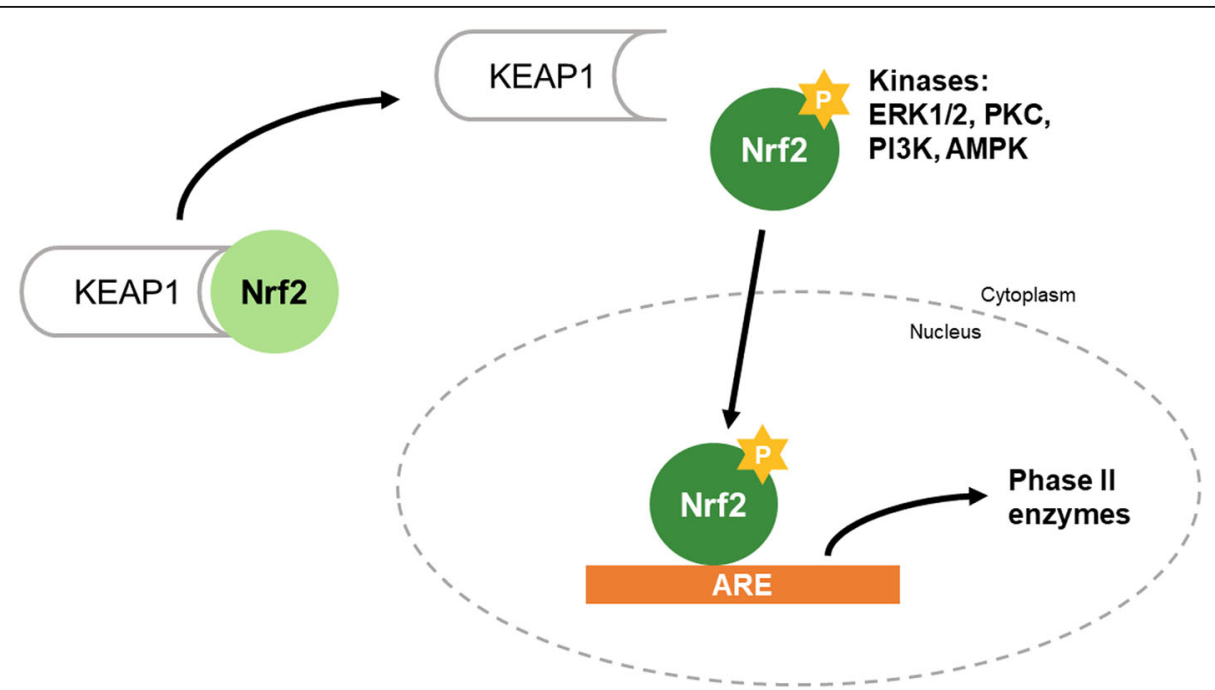

Fig. 1 Mechanism of the Nrf2 pathway. Under oxidative stress condition, Nrf2 separates from Keap1 via phosphorylation of it by various kinases. Nrf2 translocated into nucleus and binds to ARE region on promoter of the target gene including HO-1 and NQO-1 
bovine serum albumin were purchased from SigmaAldrich (St, Louis, MO, USA).

\section{Cell culture}

Hepa-1c1c7 (mouse hepatoma cells) and HepG2 (human hepatocellular carcinoma cells) were purchased from the American Type Culture Collection (ATCC, Manassas, VA, USA). The cells were maintained at sub-confluence in the presence of $95 \%$ air and $5 \% \mathrm{CO}_{2}$ in a humidified atmosphere at $37^{\circ} \mathrm{C}$. DMEM and $\alpha$-MEM were used for HepG2 and Hepa-1c1c7 cell cultivation, respectively. The media were supplemented with $10 \% \mathrm{FBS}, 100 \mathrm{U} / \mathrm{ml}$ penicillin, and $100 \mu \mathrm{g} / \mathrm{ml}$ streptomycin.

\section{Quinone reductase (QR) assay}

Specific QR activity was measured using a previously reported $Q R$ assay $[25,26]$, after brief modifications. Hepa-1c1c7 cells $\left(1 \times 10^{4}\right.$ cells/well $)$ were plated on 96-well culture plates and incubated for $24 \mathrm{~h}$ before treatment with five compounds isolated from $P$. alkekengi including physalin A (Fig. 2). The absorbance at $610 \mathrm{~nm}$ was determined five times at $50 \mathrm{~s}$ intervals using a Synergy HT multi-microplate reader (Bio-Tek Instruments, Winooski, VT, USA).

\section{Cell viability assay}

Cell viability was measured using the WST-1 cell proliferation assay kit (EZ-Cytox; Daeil Lab, Seoul). HepG2 cells $\left(1 \times 10^{4}\right.$ cells/well $)$ were plated in 96-well culture plates and incubated at $37^{\circ} \mathrm{C}$ for $24 \mathrm{~h}$, followed by treatment with various concentrations of physalin A. After $24 \mathrm{~h}$ of treatment, we added 1/10 diluted EZ-Cytox solution to each well and incubated for $1 \mathrm{~h} 20 \mathrm{~min}$. Then, absorbance was measured at $450 \mathrm{~nm}$ using Synergy HT multi-detection microplate reader.

\section{Preparation of nuclear and cytosolic fractions}

HepG2 cells $\left(6 \times 10^{5}\right.$ cells/well) were plated in 6-well culture plates and incubated for $24 \mathrm{~h}$ prior to physalin A treatment. Nuclear and cytosolic fractions were prepared using a nuclear extraction kit (Cayman, Ann Arbor, MI, USA).

\section{Western blot analysis}

HepG2 cells $\left(6 \times 10^{5}\right.$ cells/well $)$ were plated in 6-well culture plates and incubated for $24 \mathrm{~h}$ prior to physalin A treatment. Cell lysate was prepared using ice-cold radioimmunoprecipitation assay (RIPA) buffer (Thermo Scientific) containing phenylmethane sulfonyl fluoride (PMSF) and a protease inhibitor cocktail (Sigma, St. Louis, MO, USA), followed by centrifugation for $25 \mathrm{~min}$ at $4{ }^{\circ} \mathrm{C}$. Protein concentrations were determined using protein assay dye reagent concentrates (Bio-Rad, Hercules, CA, USA). Total cell lysates, and nuclear and cytosolic fractions were loaded on $10 \%$ sodium dodecyl sulfate polyacrylamide gels, electrophoresed, and then transferred to polyvinylidene difluoride membranes (Bio-Rad). The membranes were blocked using $3 \%$ bovine serum albumin (BSA), followed by incubation with primary antibodies against the following proteins:

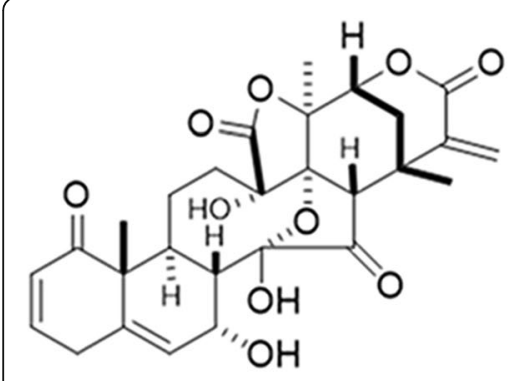

Physalin A

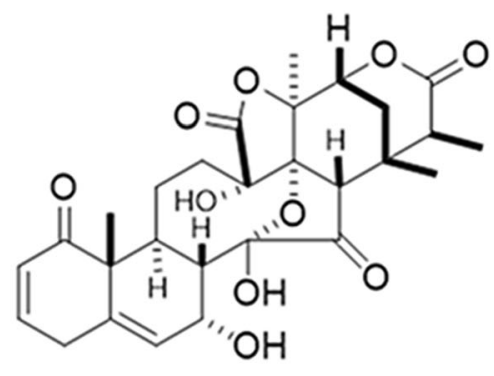

Physalin 0<smiles>O=c1cc(-c2ccc(O)c(O)c2)oc2cc(O)cc(O)c12</smiles>

Luteoiln<smiles>COC(=O)C1(O)CC(O)C(O)C(OC(=O)/C=C/c2ccc(O)c(O)c2)C1</smiles>

Methyl chlorogenic acid<smiles>O=C(Oc1cc(O)c2c(=O)cc(-c3ccc(O)c(O)c3)oc2c1)C1CCCCC1</smiles>

Luteolin-7-O-glucoside

Fig. 2 Structure of physalin A, physalin O, luteolin, methyl chlorogenic acid, and luteolin-7-O-glucoside isolated from P. alkekengi 
$\beta$-actin, NQO-1, HO-1, LaminB (Santacruz Biotechnology, Santa Cruz, CA, USA); Nrf2 (Abcam, Cambridge, MA, USA); ERK, p-ERK, p38, and p-p38 (Cell Signaling Technology, Denvers, MA, USA) in 3\% BSA. The western blots were developed using SuperSignal ${ }^{\text {Tw }}$ West Femto maximum sensitivity substrate reagent (Thermo Scientific).

\section{Total RNA extraction and quantitative reverse} transcription-polymerase chain reaction (qRT-PCR)

Total RNA was extracted from HepG2 cells using the RNeasy mini kit (Qiagen, Hilde, Germany) according to the manufacturer's instruction. cDNA was synthesized using the PrimeScript ${ }^{\text {ti }}$ first strand cDNA synthesis kit (Takara, Shiga, Japan) according to the manufacturer's instruction. qRT-PCR analysis was performed using the LC480 detection system (Roche, Basel, Switzerland).

\section{ARE reporter assay}

HepG2 cells $\left(1 \times 10^{5}\right.$ cells/well $)$ were plated in 24 -well culture plates and incubated for $24 \mathrm{~h}$, followed by physalin A treatment. The cells in each well were transfected with $0.4 \mu \mathrm{g}$ ARE-luc reporter construct containing human NQO-1 sequences and $50 \mathrm{ng}$ of pRL-CMV transfection control vector using the TransIT-2020 transfection reagent (Mirus Bio, Madison, WI, USA) according to the manufacturer's instructions. The reporter assay was performed using a dual luciferase assay kit (Promega, Madison, WI, USA) and Synergy HT multi-detection microplate reader.

\section{Oligonucleotide pull-down assay}

HepG2 cells $\left(3 \times 10^{6}\right.$ cells/well $)$ were plated in $100-\mathrm{mm}$ culture dishes and incubated for $24 \mathrm{~h}$, followed by physalin A treatment. The cells were lysed in HKMG buffer (10 mM HEPES (pH 7.9), $100 \mathrm{mM} \mathrm{KCl,} 5 \mathrm{mM} \mathrm{MgCl} 2,1 \mathrm{mM}$ dithiothreitol (DTT), 10\% glycerol and 0.5\% NP-40), and the cell lysates were incubated overnight with biotinylated oligonucleotides. The sequence of the oligonucleotide is as follows: 5'-AAATCGCAGTCAC- -AGTGACTCAGCAGAATCTGAGCCTAGG-3'. To obtain the nucleotide bound protein, the samples were incubated with streptavidin-agarose resin (Thermo Scientific) for $6 \mathrm{~h}$ at $4^{\circ}$ $\mathrm{C}$, and then washed with HKMG buffer. The washed samples were used for western blot analysis.

\section{Immunocytochemistry}

The cellular distribution of Nrf2 was determined using immunofluorescence assay and confocal microscopy as previously described [27]. In brief, HepG2 cells $\left(2 \times 10^{3}\right.$ cells/well) were plated on glass coverslips in 24-well plates, and incubated for $24 \mathrm{~h}$ prior to treatment. Next, the cells were incubated with primary antibody against Nrf2 (1:150; Cambridge, UK) overnight at $4{ }^{\circ} \mathrm{C}$. Alexa Fluor 488-conjugated anti-rabbit (Invitrogen, Carlsbad, CA, USA) secondary antibody was used at 1:200 dilution for $1 \mathrm{~h}$ at room temperature. Antibodies were diluted in phosphate buffered saline-Tween 20 (PBST) containing $5 \%$ normal serum and $0.3 \%$ Triton X-100. Images were obtained using a Leica TCS SP5 confocal system (Leica, Wetzlar, Germany).

\section{Statistical analysis}

Results were presented as mean \pm standard error of the mean (SEM). Statistical significance was determined using one-way analysis of variance (ANOVA) and Dunnett's multiple comparison test. $P<0.05$ (calculated using GraphPad Prism version 7.00) indicated statistically significant difference with respect to the control group.

\section{Results}

Physalin A induces specific QR activity

QR activity is a measure of the chemopreventive effect of any compound $[7,28]$. We first assessed the specific QR activity of the $P$. alkekengi extract and five compounds derived from this plant in Hepa-1c1c cells. Results showed that the extract and only physalin A increased specific QR activity in a dose-dependent manner (Fig. 3a-b). Other compounds, such as physalin $\mathrm{O}$, luteolin, methyl chlorogenic acid, and luteolin-7-O-glucoside did not significantly increase QR activity (Fig. 3c-f). The P. alkekengi extract and the isolated compounds did not significantly affect cell viability. Sulforaphane was used as a positive control in these experiments. These results showed that physalin A is an active component responsible for induction of $\mathrm{QR}$ activity.

\section{Physalin A induces NQO1 transcription in HepG2 cells}

Since physalin A was the active component required for QR activity, we performed cell viability assay using 3.125-100 $\mu \mathrm{M}$ physalin A (Fig. 4a) to determine the non-cytotoxic concentration range that can be used in further experiments involving HepG2 cells. No significant cytotoxicity was observed below $25 \mu \mathrm{M}$ (Fig. 4a).

To investigate whether physalin A induces QR activity through the Nrf2 pathway, we measured Nrf2 mRNA level and ARE activation. Nrf2 upregulated genes encoding phase II detoxification enzymes, such as NQO- 1 , by binding to the ARE in the target gene's promoter regions [8]. qRT-PCR and western blotting showed that physalin A increased NQO-1 mRNA expression (Fig. 4b) and the protein levels of Nrf2 target genes, respectively (Fig. 4e). To determine whether physalin A activated the ARE by promoting Nrf2 binding, we performed an oligonucleotide pull-down assay and a reporter assay using a construct containing the ARE (Fig. 4d). Also, we observed that the binding of Nrf2 to ARE was increased by physalin A in HepG2 cells in a dose-dependent manner (Fig. 4c). 


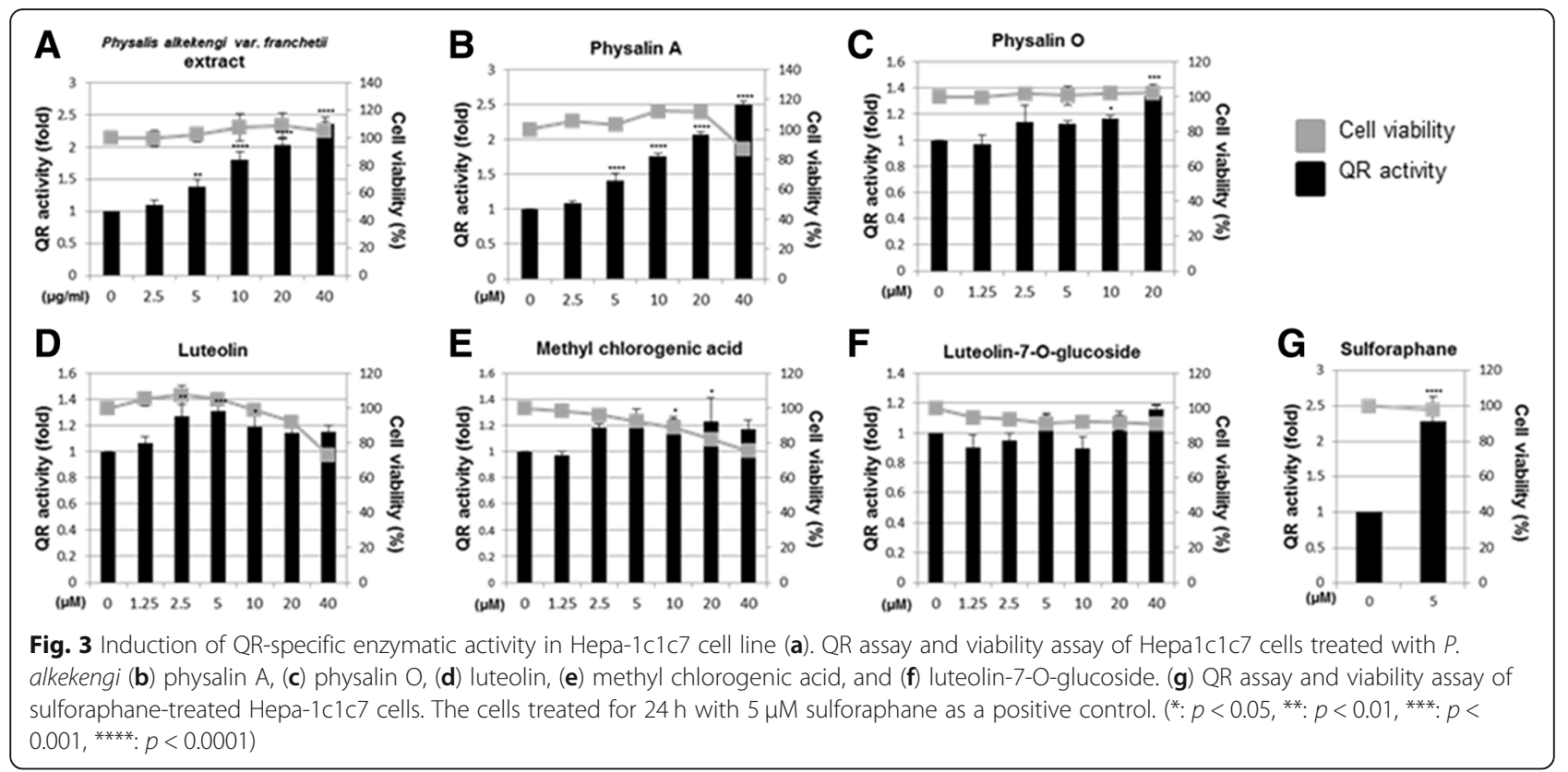

Physalin A induces Nrf2 expression and nuclear accumulation

To confirm that physalin A increases Nrf2 expression and nuclear accumulation, we assessed Nrf2 expression at various time points and monitored nuclear translocation of Nrf2 from the cytosol using fluorescent dyes. Nrf2 expression in a time-dependent manner (Fig. 5a) when the cells were treated with $20 \mu \mathrm{M}$ physalin A. We also observed that physalin A increased Nrf2 nuclear accumulation in dose-dependent manner (Fig. 5b-c) when the cells were treated for $4 \mathrm{~h}$. Thus, these results showed that physalin A induces Nrf2 expression and nuclear accumulation.

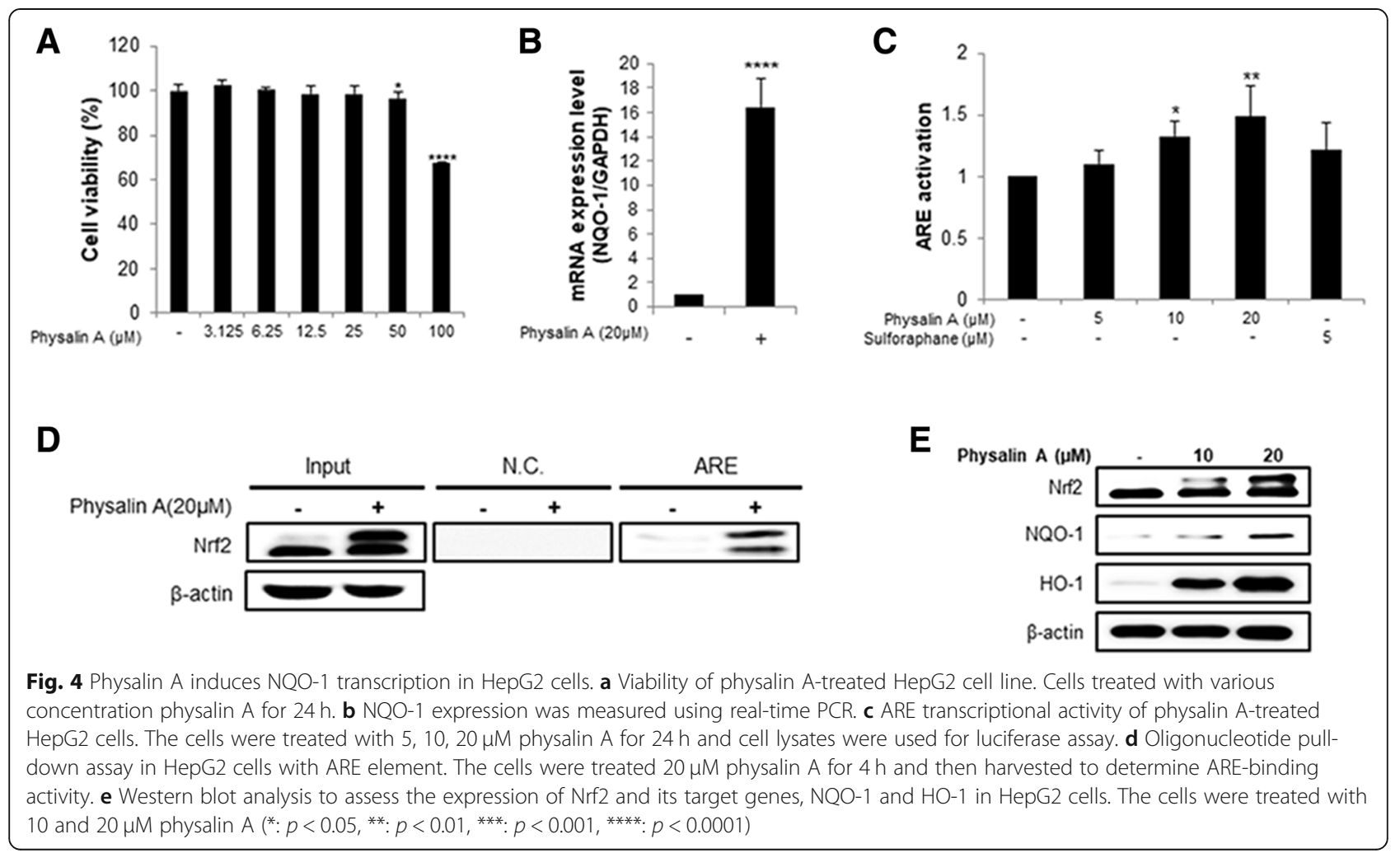




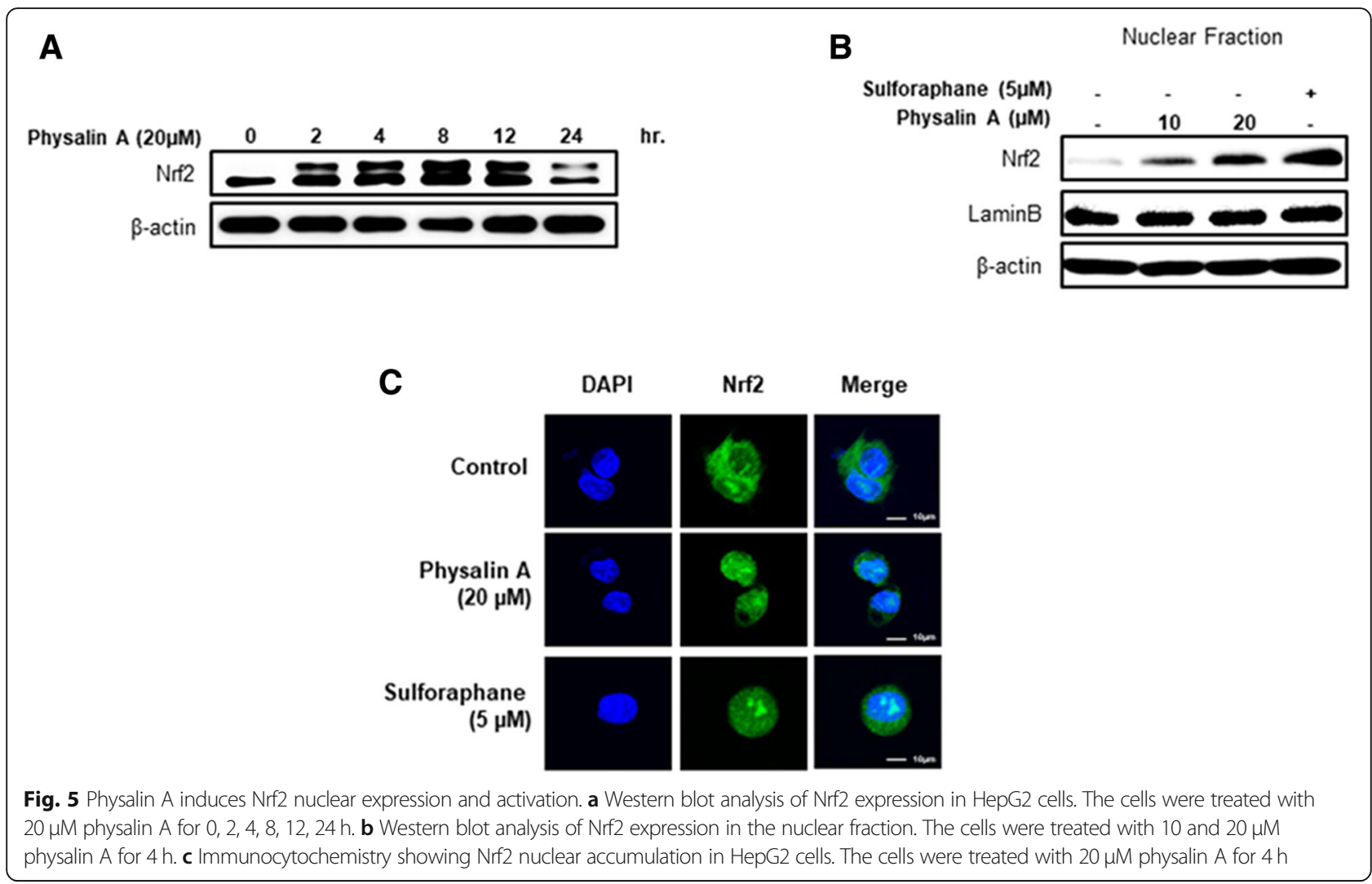

\section{Physalin A induces Nrf2 activation via ERK and the p38 kinase}

A previous study showed that multiple kinases are involved in the translocation of Nrf2 to the nucleus [11-14]. To identify the kinases required for physalin A-mediated Nrf2 translocation, we assessed Nrf2 expression after pretreatment with several following kinase inhibitors: LY294002 (inhibitor of PI3K), SP600125 (inhibitor of JNK), U0126 (inhibitor of ERK), or SB202190 (inhibitor of p38). Particularly, treatments with U0126 (inhibitor of ERK) and SB202190 (inhibitor of p38) reduced Nrf2 nuclear accumulation (Fig. 6a). To further confirm if ERK and p38 regulate Nrf2 activation, the phosphorylated-forms of ERK and p38 were investigated in a time-dependent manner. We observed that physalin A increases ERK and p38 phosphorylation. We also determined the expression of $\mathrm{HO}-1$, one of the target genes, in cells treated with physalin A and U0126 or SB202190. Results showed that the expression of Nrf2 and its target genes was considerably reduced after cotreatment with the inhibitor compared to treatment with physalin A alone (Fig. 6c). Thus, these results suggest that physalin A activates the ERK and p38 kinases to induce Nrf2 nuclear translocation.

\section{Discussion}

Physalin A, isolated from $P$. alkekengi, is a triterpenoid with a steroid skeleton, which shows anti-cancer activity in various cancer cell lines [21, 23, 29, 30]. Terpenoids are organic chemicals composed of isoprene units and many of them are of plant origin [31]. The majority of terpenoids also possess pharmacological properties, including anti-cancer, anti-inflammatory, anti-viral, and anti-fungal activities [31, 32]. Several studies have shown that terpenoids show anti-cancer activity via MAPK phosphorylation, including ERK and p38, in various cancers [33-35]. In this study, physalin A increased the expression of detoxification enzymes by activating the Nrf2 pathway via ERK and p38. Therefore, we speculated that these results might be related to terpenoid structure. Interestingly, although physalin $\mathrm{A}$ and $\mathrm{O}$ have a similar structure, physalin A activated Nrf2 expression and induced phase II detoxification enzymes, whereas physalin $\mathrm{O}$ showed no significant effect on $\mathrm{QR}$ activity. The sole difference in structure between the two compounds is a double bond between $C_{25}$ and $C_{27}$ [24], which possibly contributed to the difference in biological activity.

We observed that physalin A activated the Nrf2-ARE signaling pathway through ERK and p38 phosphorylation at different time points (Fig. 6b). While ERK phosphorylation was observed from $15 \mathrm{~min}$ and peaked at 45 min, p38 phosphorylation increased from $60 \mathrm{~min}$ onwards. These results suggest that ERK phosphorylation triggers Nrf2 translocation at early time points (within $30 \mathrm{~min}$ ), followed by p38 kinase phosphorylation at later 


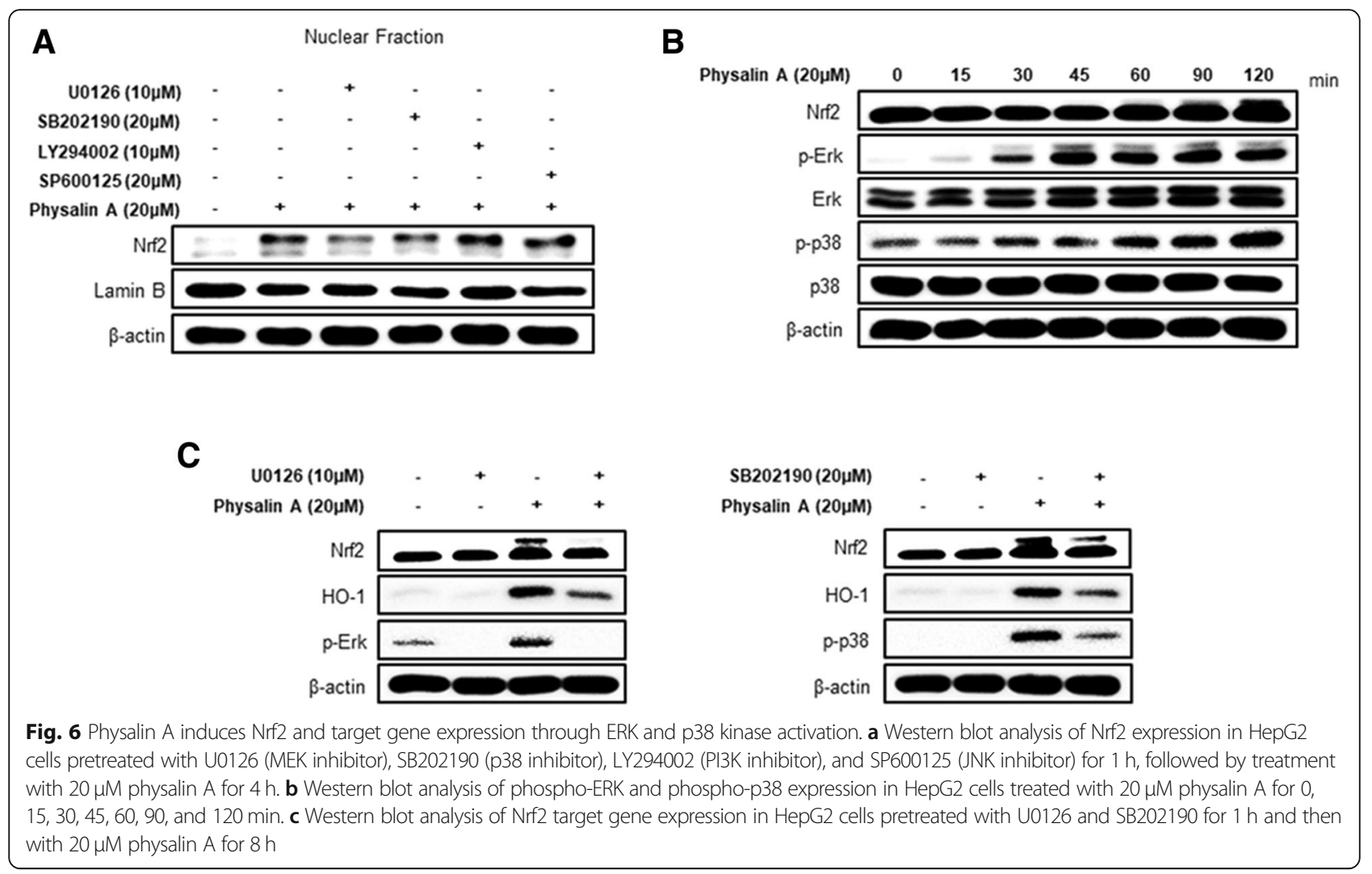

time points, which induces $\mathrm{Nrf} 2$ translocation and nuclear accumulation. Furthermore, our results suggest that it is not possible to exclude the effect of other transcription factors and upstream signaling molecules in modulating the expression of Nrf2 and its target genes, because ERK and p38 kinase inhibitors do not completely abrogate physalin A-induced Nrf2 expression and nuclear accumulation. Further studies on the differential temporal regulation of these kinases and involvement of other factors are required.

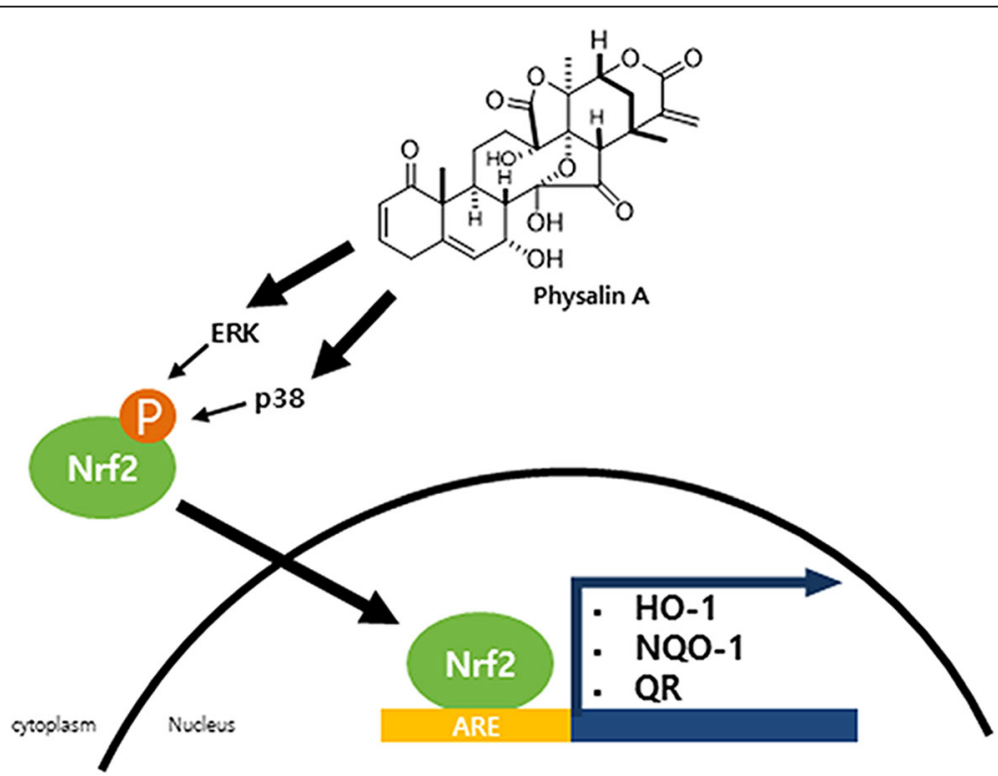

Fig. 7 The hypothetical Nrf2 pathway model induced by physalin A. Physalin A induces the Nrf2 activation and nuclear translocation through Erk or p38 kinase phosphorylation. In the nucleus, ARE binding of Nrf2 induces detoxification gene expression such as NQO-1, HO-1, and QR. 
As an upstream key factor that increases detoxifying enzyme activity, Nrf2 regulates the expression of several target genes. Here, we showed that physalin A induces Nrf2 activation and the expression of its target genes, NQO-1 and $\mathrm{HO}-1$. However, these target genes were not expressed to similar extents at the same time point. Previously, [36] demonstrated differential regulation of $\mathrm{HO}-1$ and NQO-1 by ethanol. Ethanol-induced HO-1 expression was regulated by Nrf2, HIF- $1 \alpha$, and JNK, whereas that of NQO-1 was regulated by Nrf2 and Src kinase. Thus, we speculated that the target genes of Nrf2 induced by physalin A, including NQO-1 and HO-1, may be regulated by different kinases and other factors, respectively.

Post nuclear translocation, Nrf2 may be phosphorylated by an upstream kinase or stabilized by Keap1 modifications. Several dietary phytochemicals cause Keap1-specific cysteine thiol group oxidation or chemical modification. Sulforaphane induces phosphorylation of Nrf2 upstream of the p38 MAP kinase, and Nrf2 stabilization and nuclear accumulation by specific modifications of Keap1 [12, 37, 38]. However, we have not investigated whether physalin A regulates conformational changes of Keap1 in the cytosol. The additional study of the keap 1 modification should be required in the future studies.

\section{Conclusions}

In conclusion, we showed that physalin A increased detoxifying enzyme expression via activation of $\mathrm{Nrf} 2$ and its target genes. The results of the QR assay showed that physalin A might suppress cancer development at the initial stage of carcinogenesis by regulating the activity of phase II detoxification enzymes (Fig. 7). These results showed that physalin $\mathrm{A}$ is a potential chemopreventive agent that regulates Nrf2 pathway in liver cancer.

\begin{abstract}
Abbreviations
ARE: Antioxidant response element; p38: p38 mitogen-activated protein kinase; ERK1/2: Extracellular signal-regulated kinase; JNK: C-Jun N-terminal kinase; PKC: Protein kinase C; AMPK: AMP-activated protein kinase; PI3K: Phosphatidylinositide 3-kinases; HO-1: Heme oxygenase 1; Nrf2: Nuclear factor erythroid 2-related factor 2; NQO1: NAD(P)H quinone dehydrogenase
\end{abstract} 1; QR: Quinone reductase

\section{Acknowledgements}

The authors acknowledge Dr. Hak Cheol Kwon, Natural product informatics research center, KIST Gangneung institute of Natural Products, for in authentication of plant materials.

\section{Funding}

This work was supported by the National Research Council of Science \& Technology (NST) grant by the Korea government (MSIP) (2N43500), by intramural grant (2Z05310) and (2Z05630) from the Korea Institute of Science and Technology (KIST), Republic of Korea. This funding body was not included the design of the study or analysis, or interpretation of the results.

\section{Availability of data and materials}

All the data used the current study are available with the corresponding author on reasonable request.

\section{Authors' contributions}

$J M S, K L, H J L, J H Y$ and $C W N$ contributed to this study. JMS wrote the manuscript and conducted almost experiment including interpretation of data. JMS and KL contributed to the design of the study. HJL prepared the plant material and isolated these compounds, $\mathrm{JHY}$ prepared some of the figures and CWN provided supervision of this study. All authors reviewed the manuscript prior to submission. All authors read and approved the final manuscript.

Ethics approval and consent to participate

Not applicable.

\section{Consent for publication}

Not applicable.

\section{Competing interests}

The authors declare that they have no competing interests.

\section{Publisher's Note}

Springer Nature remains neutral with regard to jurisdictional claims in published maps and institutional affiliations.

\section{Author details}

${ }^{1}$ Natural Products Research Center, Korea Institute of Science and Technology (KIST) Gangneung Institute of Natural Products, Gangneung, Gangwon-do 25451, Republic of Korea. ${ }^{2}$ Division of Bio-Medical Science \&Technology, KIST School, Korea University of Science and Technology, Seoul 02792, Republic of Korea. ${ }^{3}$ Systems Biotechnology Research Center, Korea Institute of Science and Technology (KIST) Gangneung Institute of Natural Products, Gangneung, Gangwon-do 25451, Republic of Korea.

Received: 17 October 2018 Accepted: 18 April 2019

Published online: 09 May 2019

References

1. Stagos D, Amoutzias GD, Matakos A, Spyrou A, Tsatsakis AM, Kouretas D. Chemoprevention of liver cancer by plant polyphenols. Food Chem Toxicol. 2012;50(6):2155-70.

2. Jemal A, Bray F, Center MM, Ferlay J, Ward E, Forman D. Global cancer statistics. CA Cancer J Clin. 2011;61(2):69-90.

3. Penny LK, Wallace HM. The challenges for cancer chemoprevention. Chem Soc Rev. 2015;44(24):8836-47.

4. Nejad ASM, Bahmani M, Shah NA, Shah SA, Rafieian-Kopaei M. Beliefs of herbal therapies of the community of the llam city of llam province, Iran. J Pharm Pharmacognosy Res. 2018;6(4):299-317.

5. Jalali H, Nejad AM, Ebadi A, Laey G. Ethnobotany and folk pharmaceutical properties of major trees or shrubs in northeast of Iran. Asian J Chem. 2009; 21(7):5632.

6. Lenzi M, Fimognari C, Hrelia P. Sulforaphane as a promising molecule for fighting cancer. Cancer Treat Res. 2014;159:207-23.

7. Yun JH, Lee SB, Kang K, Lee EH, Lee HJ, Jung SH, Nho CW. Bifunctional chemopreventive effects of Adenocaulon himalaicum through induction of detoxification enzymes and apoptosis. J Med Food. 2013;16(8):701-10.

8. Yu X, Kensler T. Nrf2 as a target for cancer chemoprevention. Mutat Res. 2005:591(1-2):93-102

9. Wakabayashi N, Dinkova-Kostova AT, Holtzclaw WD, Kang MI, Kobayashi A, Yamamoto M, Kensler TW, Talalay P. Protection against electrophile and oxidant stress by induction of the phase 2 response: fate of cysteines of the Keap1 sensor modified by inducers. Proc Natl Acad Sci U S A. 2004;101(7):2040-5.

10. Lee JS, Surh YJ. Nrf2 as a novel molecular target for chemoprevention. Cancer Lett. 2005;224(2):171-84.

11. Sun Z, Huang Z, Zhang DD. Phosphorylation of Nrf2 at multiple sites by MAP kinases has a limited contribution in modulating the Nrf2-dependent antioxidant response. PLoS One. 2009;4(8):e6588.

12. Surh YJ, Kundu JK, Na HK. Nrf2 as a master redox switch in turning on the cellular signaling involved in the induction of Cytoprotective genes by some Chemopreventive phytochemicals. Planta Med. 2008;74(13):1526-39.

13. Bloom DA, Jaiswal AK. Phosphorylation of Nrf2 at Ser40 by protein kinase $C$ in response to antioxidants leads to the release of Nrf2 from INrf2, but is not required for Nrf2 stabilization/accumulation in the nucleus and transcriptional activation of antioxidant response element-mediated 
NAD(P)H:quinone oxidoreductase-1 gene expression. J Biol Chem. 2003; 278(45):44675-82.

14. Zipper LM, Mulcahy RT. Erk activation is required for Nrf2 nuclear localization during pyrrolidine dithiocarbamate induction of glutamate cysteine ligase modulatory gene expression in HepG2 cells. Toxicol Sci. 2003;73(1):124-34.

15. Yang C, Zhang X, Fan H, Liu Y. Curcumin upregulates transcription factor Nrf2, HO-1 expression and protects rat brains against focal ischemia. Brain Res. 2009;1282:133-41.

16. Prochaska HJ, Talalay P. Purification and characterization of two isofunctional forms of $\mathrm{NAD}(\mathrm{P}) \mathrm{H}$ : quinone reductase from mouse liver. J Biol Chem. 1986;261(3):1372-8.

17. Chao C, Zhang ZF, Berthiller J, Boffetta P, Hashibe M. NAD(P)H:quinone oxidoreductase 1 (NQO1) Pro187Ser polymorphism and the risk of lung, bladder, and colorectal cancers: a meta-analysis. Cancer Epidemiol Biomark Prev. 2006;15(5):979-87.

18. Zhang J, Schulz WA, Li Y, Wang R, Zotz R, Wen D, Siegel D, Ross D, Gabbert HE, Sarbia M. Association of NAD(P)H: quinone oxidoreductase 1 (NQO1) C609T polymorphism with esophageal squamous cell carcinoma in a German Caucasian and a northern Chinese population. Carcinogenesis. 2003:24(5):905-9.

19. Bahmani M, Rafieian-Kopaei M, Naghdi N, Nejad ASM, Afsordeh O. Physalis alkekengi: a review of its therapeutic effects. J Chem Pharm Sci. 2016;9(3):1472-85.

20. Qiu L, Zhao F, Jiang ZH, Chen LX, Zhao Q, Liu HX, Yao XS, Qiu F. Steroids and flavonoids from Physalis alkekengi var. franchetii and their inhibitory effects on nitric oxide production. J Nat Prod. 2008;71(4):642-6.

21. Han H, Qiu L, Wang X, Qiu F, Wong Y, Yao X. Physalins a and B inhibit androgen-independent prostate cancer cell growth through activation of cell apoptosis and downregulation of androgen receptor expression. Biol Pharm Bull. 2011;34(10):1584-8.

22. He H, Zang LH, Feng YS, Wang J, Liu WW, Chen LX, Kang N, Tashiro S, Onodera S, Qiu F, et al. Physalin a induces apoptotic cell death and protective autophagy in HT1080 human fibrosarcoma cells. J Nat Prod. 2013;76(5):880-8.

23. Kang N, Jian JF, Cao SJ, Zhang Q, Mao YW, Huang YY, Peng YF, Qiu F, Gao XM. Physalin a induces G2/M phase cell cycle arrest in human non-small cell lung cancer cells: involvement of the p38 MAPK/ROS pathway. Mol Cell Biochem. 2016;415(1-2):145-55.

24. Kawai M, Ogura T, Makino B, Matsumoto A, Yamamura H, Butsugan Y, Hayashi M. Physalins N and O from Physalis alkekengi. Phytochemistry. 1992; 31(12):4299-302.

25. Fahey JW, Dinkova-Kostova AT, Stephenson KK, Talalay P. The "Prochaska" microtiter plate bioassay for inducers of NQO1. Methods Enzymol. 2004;382: 243-58.

26. Lee SB, Cha KH, Selenge D, Solongo A, Nho CW. The chemopreventive effect of taxifolin is exerted through ARE-dependent gene regulation. Biol Pharm Bull. 2007;30(6):1074-9.

27. Yun JH, Lee SB, Lee HJ, Kim CY, Kim MA, Sohn YC, Nho CW. Bi-functional induction of the quinone reductase and cytochrome P450 1A1 by youngiasides via Nrf2-ARE and AhR-XRE pathways. Biol Pharm Bull. 2010; 33(10):1650-7

28. Prestera T, Holtzclaw WD, Zhang Y, Talalay P. Chemical and molecular regulation of enzymes that detoxify carcinogens. Proc Natl Acad Sci U S A. 1993;90(7):2965-9.

29. Matsuura T, Kawai M, Makashima R, Butsugan Y. Structures of physalin a and physalin B, 13,14-seco-16,24-cyclo-steroids from Physalis alkekengi var. Francheti. J Chem Soc Perkin. 1970;5:664-70.

30. Zhu F, Dai C, Fu Y, Loo JF, Xia D, Gao SP, Ma Z, Chen Z. Physalin a exerts antitumor activity in non-small cell lung cancer cell lines by suppressing JAK/STAT3 signaling. Oncotarget. 2016;7(8):9462-76.

31. Rabi T, Bishayee A. Terpenoids and breast cancer chemoprevention. Breast Cancer Res Treat. 2009;115(2):223-39.

32. Wagner KH, Elmadfa I. Biological relevance of terpenoids. Overview focusing on mono-, di- and tetraterpenes. Ann Nutr Metab. 2003:47(3-4):95-106.

33. Lee KM, Kwon TY, Kang U, Seo EK, Yun JH, Nho CW, Kim YS. Tussilagononeinduced Nrf2 pathway activation protects HepG2 cells from oxidative injury. Food Chem Toxicol. 2017;108(Pt A:120-7.

34. Hsia TC, Yu CC, Hsiao YT, Wu SH, Bau DT, Lu HF, Huang YP, Lin JG, Chang SJ, Chung JG. Cantharidin impairs cell migration and invasion of human lung Cancer NCl-H460 cells via UPA and MAPK signaling pathways. Anticancer Res. 2016;36(11):5989-97.
35. Li Y, Wen JM, Du CJ, Hu SM, Chen JX, Zhang SG, Zhang N, Gao F, Li SJ, Mao $X W$, et al. Thymol inhibits bladder cancer cell proliferation via inducing cell cycle arrest and apoptosis. Biochem Biophys Res Commun. 2017;491 (2):530-6.

36. Yeligar SM, Machida K, Kalra VK. Ethanol-induced HO-1 and NQO1 are differentially regulated by HIF-1alpha and Nrf2 to attenuate inflammatory cytokine expression. J Biol Chem. 2010;285(46):35359-73.

37. Keum YS, Yu S, Chang PP, Yuan X, Kim JH, Xu C, Han J, Agarwal A, Kong AN Mechanism of action of sulforaphane: inhibition of p38 mitogen-activated protein kinase isoforms contributing to the induction of antioxidant response element-mediated heme oxygenase-1 in human hepatoma HepG2 cells. Cancer Res. 2006;66(17):8804-13.

38. Dinkova-Kostova AT, Fahey JW, Kostov RV, Kensler TW. KEAP1 and done? Targeting the NRF2 pathway with sulforaphane. Trends Food Sci Tech. 2017; 69:257-69.
Ready to submit your research? Choose BMC and benefit from:

- fast, convenient online submission

- thorough peer review by experienced researchers in your field

- rapid publication on acceptance

- support for research data, including large and complex data types

- gold Open Access which fosters wider collaboration and increased citations

- maximum visibility for your research: over $100 \mathrm{M}$ website views per year

At $\mathrm{BMC}$, research is always in progress.

Learn more biomedcentral.com/submissions 